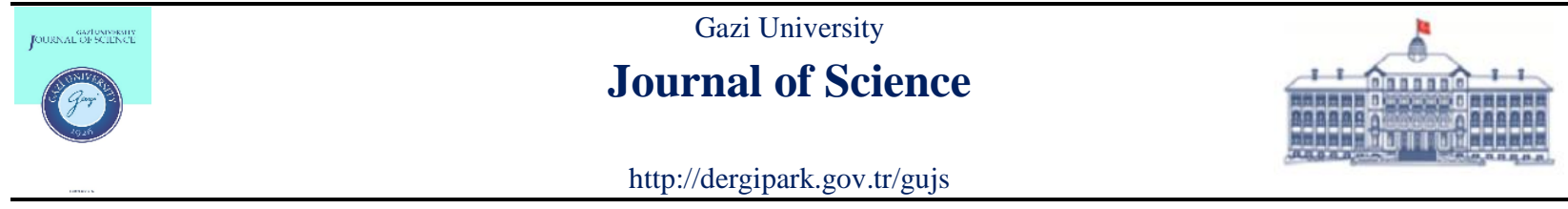

\title{
Carbon Microrod Material Derived from Human Hair and Its Electrochemical Supercapacitor Application
}

\author{
Derya BAL ALTUNTAS ${ }^{*}$ (i) , Sema ASLAN ${ }^{2}$ (i) , Vagif NEVRUZOGLU ${ }^{3}$ (i) \\ ${ }^{1}$ Recep Tayyip Erdogan University, Faculty of Engineering, Department of Bioengineering, 53100, Rize, Turkey \\ ${ }^{2}$ Mugla Sitki Kocaman University, Faculty of Science, Department of Chemistry, 48170, Mugla, Turkey \\ ${ }^{3}$ Recep Tayyip Erdogan University, Faculty of Engineering Department of Energy Systems Engineering, 53100, Rize, Turkey
}

\section{Highlights}

-Activated carbon from waste Turkish human hair.

-Activated with $\mathrm{Na}_{2} \mathrm{CO}_{3}$ at different temperatures.

-HHC-250 samples have microrod shaped porous structure, providing divergent surface functional groups

\section{Article Info}

Received:01 Apr 2020

Accepted:24 Dec 2020

\section{Keywords}

Human hair

Supercapacitors

Electrochemical

application

Carbon

Microrod

\begin{abstract}
Here, Turkish human hair fibers were used as a carbon source at the synthesis of human hairsourced activated carbons (HHC). During the synthesis of HHCs sodium carbonate $\left(\mathrm{Na}_{2} \mathrm{CO}_{3}\right)$ was added to the synthesis process for an elevated activation by calcination at different temperatures. Then obtained HHCs utilized for the modification of carbon paste electrode to evaluate the supercapacitance performance of this activated HHC. Electrochemical investigation of the HHC modified electrodes have been carried out by employing differential pulse voltammetry (DPV), cyclic voltammetry $(\mathrm{CV})$ and electrochemical impedance spectroscopy (EIS) measurements. The pore and surface properties and chemical structure of the HHCs were investigated by scanning electron microscopy (SEM), Brunauer-Emmett and Teller (BET) analysis and Raman spectroscopy. HHCs displayed a Type-IV isotherm, which indicates the existence of micromesoporous structure on the surface. Carbonization of the waste hair was performed by calcination to improve the pore facilities at three different temperatures $\left(200-250-300{ }^{\circ} \mathrm{C}\right)$. The sample was named $\mathrm{HHC}-250$ (HHC calcinated at $250^{\circ} \mathrm{C}$ ) exhibited the best charge storage capacity when used at the modification of carbon paste electrode, among other HHCs with a 26.88 $\mathrm{F} \mathrm{g}^{-1}$ specific capacitance value (in $6 \mathrm{M} \mathrm{KOH}$ at a scan rate of $100 \mathrm{mV} \mathrm{s}^{-1}$ ). Also, a very attainable supercapacitance stability was achieved from HHC-250 modified electrode after 1000 cycles. The presented electrode system exhibited an energy density of $3.73 \mathrm{~W} \mathrm{~h} \mathrm{~kg}$. This work can serve as a guideline for optimizing the performance of hair like biomass-derived carbons by matching their pore properties and detailed electrochemical performance investigations.
\end{abstract}

\section{INTRODUCTION}

Supercapacitors (SC), or electrochemical double-layer capacitors (EDLCs), extend the battery life of the devices and serve as a short-term backup power supply for electrical devices [1] To meet the energy needs of electric vehicles additional researches are particularly focused on electrode material. SCs can receive and distribute energy more quickly than batteries [2]. This means that in electric vehicle applications, a vehicle's charging time is reduced. However, the biggest obstacle to this is that the energy storage capacity of the SCs is very low compared to the batteries [3]. SCs can perform an infinite number of charging and discharging cycles. However, batteries lose their chargeability after reaching a certain number of cycles [4]. SCs have three types: 1) EDLCs, 2) pseudocapacitors, and 3) hybrid capacitors [5]. EDLCs store charge by the non-faradaic mechanism. In this mechanism physical processes dominate the distribution of charges the surfaces [6]. In the field of EDLCs, porous activated carbon [7], onion-like carbons [8], graphene [9,10], carbon nanotubes (CNTs) [11], nanodiamonds and nanosheets, etc. are very popular carbon-based electrode materials [12-16]. Since the energy storage therewithal the capacitance in EDLCs increases generally 
according to the affinity of electrolyte ions to the large specific conductive surface of the electrode, the pores of electrode material needed to be amplified [17]. Comperatively activated carbon has been the highly desirable electrode material among the other forms of carbon materials for EDLC applications due to possessing rich micro-, meso- and macropores. [18]. To enhance the pore distribution and increase the surface area of activated carbons, there have been reported many activation studies $\left(\mathrm{ZnCl}_{2}\right.$ [19], $\mathrm{KOH}$ [20], $\left.\mathrm{H}_{3} \mathrm{PO}_{4}[21]\right)$ which are intensively employed at the SCs [22].

The composite electrode structure of the carbon paste electrode gives an easy preparation opportunity to have high capacitance and conductivity with the help of the desired modifier [23]. The carbon paste electrodes have very low cost and provides simple design advantages including modification with various nanoparticles. Its surface is easily renewable. Also, it has very low ohmic resistance and wide potential area [24].

Production of activated carbon through chemical activation and increasing the absorption properties of these modifier materials are commonly reported [18]. In this study, it was also determined that micro/mesopore densities were increased in the $\mathrm{Na}_{2} \mathrm{CO}_{3}$ treated samples [25]. $\mathrm{Na}_{2} \mathrm{CO}_{3}$ has the function of promoting carbon atoms [26]. Conventional activated carbon production methods are mainly based on using coal, petroleum or by-products as a carbon source [27]. However, compared with these petroleum originated resins, the biomass (waste)-based activated carbon production ways are preferred as being cost-effective and environmentally friendly [28]. These sources can be multiplied (plant fragments [29-32], coal residue [33], dung [34], bone [35], fungi [36], animal or nutshells [37-39], human hair [40] but among them, hair comes forward with the need of waste management territories in Turkey.

Recycling, waste disposal has been the most important agenda of G20 decisions. Environmental pollution is rapidly increasing due to population growth and urbanization. The vast amount of human hair wastes produced by countless hairdressers in the world, and are disposed of by burning them. Due to the high $\mathrm{N}$ content of human hair, this causes the release of some toxic gases as a result of the combustion process and eventually triggers global warming [41].

Otherwise, leaving human hair wastes at waste collection centers causes microbiological health problems due to the organic properties of oily hair follicules. For these reasons, the use of human hair as biomass becomes important.

From the above literature studies, it has been found that human hair is a great activated carbon source with the disulfide bonds. An average hair composition is comprised of about $51 \%$ carbon, $21 \%$ oxygen, $6 \%$ hydrogen, $17 \%$ nitrogen, $5 \%$ sulfur, and trace amounts of iron, arsenic, magnesium, chromium, and other minerals [42]. In this study, we demonstrate a detailed search on the synthesis and electrochemical behavior of heteroatom-doped carbon materials by the carbonization of human hair [16].

It was found that micro/meso-pore content at low temperatures could be used in many areas in terms of being biocompatible [43]. Thus, waste human hair can be considered as a source in the production of activated carbon [44]. It was concluded that the activation method used was effective for the synthesis of activated carbon [45]. The activation process with $\mathrm{Na}_{2} \mathrm{CO}_{3}$ is based on the impregnation of material with a $\mathrm{Na}_{2} \mathrm{CO}_{3}$ solution and heating up to $90-100^{\circ} \mathrm{C}$. During the activation process, $\mathrm{Na}_{2} \mathrm{CO}_{3}$ causes the increment of the carbon content in the activated carbon structure [46]. Only a few investigations have described the development of activated carbon from this type of biomass-based carbon material and its utilization at the electrode modification [43-47]. When the human hair is subjected to heat treatment due to its anisotropic properties, the sulfur pressure in the medulla (the innermost layer of the hair) increases and causes small bangs [48]. Thus, it becomes a porous structure in a short time with low temperatures.

Here we have presented a porous human hair-sourced activated carbon that has been synthesized by a chemical activation method. The pore size and surface area of HHCs were investigated for different activation temperatures. As a result, it was found that optimized HHC-250 showed a high specific surface area and exhibited the best SC behavior when used at the electrode modification. 


\section{MATERIAL METHOD}

\subsection{Apparatus}

$\mathrm{Na}_{2} \mathrm{CO}_{3}$ used in the chemical activation process was obtained from Sigma-Aldrich firm. Graphite powder, mineral oil, were purchased from Sigma-Aldrich. Potassium chloride $(\mathrm{KCl})$ was obtained from Merck, so as the following potassium dihydrogen phosphate $\left(\mathrm{KH}_{2} \mathrm{PO}_{4}\right)$ and potassium hydroxide $(\mathrm{KOH})$. The metal impregnated HHC was investigated by Rigaku to make Smart Crystallographic analyzer. Before the measurements, the surface of the samples was coated with Au. JEOL Brand JSM 6610 scanning electron microscope (SEM) was utilized for the morphological characterizations of samples. $10 \mathrm{kV}$ acceleration voltage is applied in a vacuum environment. Brunauer, Emmett and Teller (BET) method is applied to determine the pore characteristics, surface area and pore size of the produced HHC by using Quantachrome Instruments Nova 4200. Micro Raman spectroscopy analyses were carried out with Witec Alpha $300 \mathrm{R}$. For the electrochemical measurements, Autolab PGSTAT 204 potentiostat/galvanostat (Metrohm Autolab B.V.) system donated with NOVA 2.1.4 software is used.

\subsection{HHC Synthesis and Activation}

In this study, the waste of human hair was rinsed with distilled water and dried. $\mathrm{Na}_{2} \mathrm{CO}_{3}$ was then used as the chemical activator, which means to improve the pore structure of the waste hair sourced activated carbon. Carbonization of the waste hair was carried out at three different temperatures (200-250-300 $\left.{ }^{\circ} \mathrm{C}\right)$. The samples were named as HHC-200; HHC-250 and HHC-300. 1/2 (w/w) ratio was applied as a raw material-activator ratio. Carbonization time was determined as 30 minutes. $1 \mathrm{~g}$ of waste human hair and 2 $\mathrm{g}$ of $\mathrm{Na}_{2} \mathrm{CO}_{3}$ were weighed and placed in a beaker. Then the resulting mixture was maintained at $105{ }^{\circ} \mathrm{C}$ ( $24 \mathrm{~h}$ ). The obtained sample was then transferred to the carbonization. It was carried out in an inert nitrogen atmosphere for 30 minutes in a $200{ }^{\circ} \mathrm{C}$ tube furnace $\left(100 \mathrm{cc} / \mathrm{g}, 10^{\circ} \mathrm{C} / \mathrm{min}\right)$. After the sample was taken from the oven, it was filtered by washing with distilled hot water to remove the ash. This procedure was repeated three times. The resulting $\mathrm{HHC}$ was dried at $105{ }^{\circ} \mathrm{C}$ for 24 hours.

\subsection{Modification of the Electrodes With HHC, Electrochemical Measurements, and Calculations}

The paste of the electrode was prepared by mixing with mineral oil in the ratio of 70:30 (w/w \%). The HHC modification is achieved by the addition of optimized amount of HHC into the paste. Autolab PGSTAT 204 potentiostat/galvanostat (Metrohm Autolab B.V.) was employed for the electrochemical measurements. A three electrodes system (platinum electrode (CH Instruments Inc. CHI 111); counter, $\mathrm{Ag} / \mathrm{AgCl}$ (containing 3.0 M KCl, CHI115); reference electrode and working electrode; HHC composite electrode) was run in $6 \mathrm{M} \mathrm{KOH}$ electrolyte. Cyclic voltammetry (CV) measurements were recorded at the scan rate of 5 to $100 \mathrm{mV} \mathrm{s}^{-1}$. Differential pulse voltammetry (DPV) measurements were carried out for the optimizations. EIS was measured in a frequency range of $10^{-1}$ to $10^{4} \mathrm{~Hz}$ in $6 \mathrm{M} \mathrm{KOH}$ solution.

The paste was prepared as mentioned above, then packed firmly into the Delrin electrode's cavity (3.0 mm diameter, $5.0 \mathrm{~mm}$ depth). The surface of the paste filled electrode was polished with a wax-paper to avoid air bubbles remaining on the electrode surface and to prevent poor or irreproducible responses. The surface of the electrode and the measurement medium was renewed before every measurement. Deionized water is used for the solutions. Experiments are conducted at room temperature and triplicated.

The specific capacitance measurements of the electrodes were examined by CV measurements at different scan rates or applying multiple cycles. Specific capacitance (Csp) values were calculated from the Equation (1)

$$
C_{S p}=\frac{1}{m \Delta V S} \int I(V) d V .
$$

Herein Csp is the specific capacitance, $\mathrm{I}$ is current, $\mathrm{S}$ is the scan rate applied, $\mathrm{m}$ is the mass of the electroactive species on the electrode surface, $\Delta \mathrm{V}$ is the potential range, respectively. The specific energy $\left(\mathrm{W} \mathrm{h} \mathrm{kg}^{-1}\right)$ was calculated from the Equation (2) [49]

$$
E=\frac{1}{2}\left(\frac{1}{3.6}\right)\left(C_{S p} \Delta V^{2}\right)
$$




\section{THE RESEARCH FINDINGS AND DISCUSSION}

\subsection{Characterization of HHC Samples}

In Figure $1 \mathrm{SEM}$ images of the $\mathrm{HHC}$ samples that activated at $200-250-300{ }^{\circ} \mathrm{C}$ temperatures in $\mathrm{Na}_{2} \mathrm{CO}_{3}$ including medium are given respectively. More abundant pores were obtained for the $250{ }^{\circ} \mathrm{C}$ treated activation process. Herein, it has been realized that different SEM images obtained for different temperature treatments, especially pore formation are realized mostly at the SEM figure of HHC-250 sample. Hybrid dislocations (cracks in the structure) were formed as a result of explosions in the HHC-250 structure. Such a defect in the structure prevented excessive pore formation. In other examples, the pores in the pore structures did not form in the form of dislocation. The density of the meso-pores is due to them.
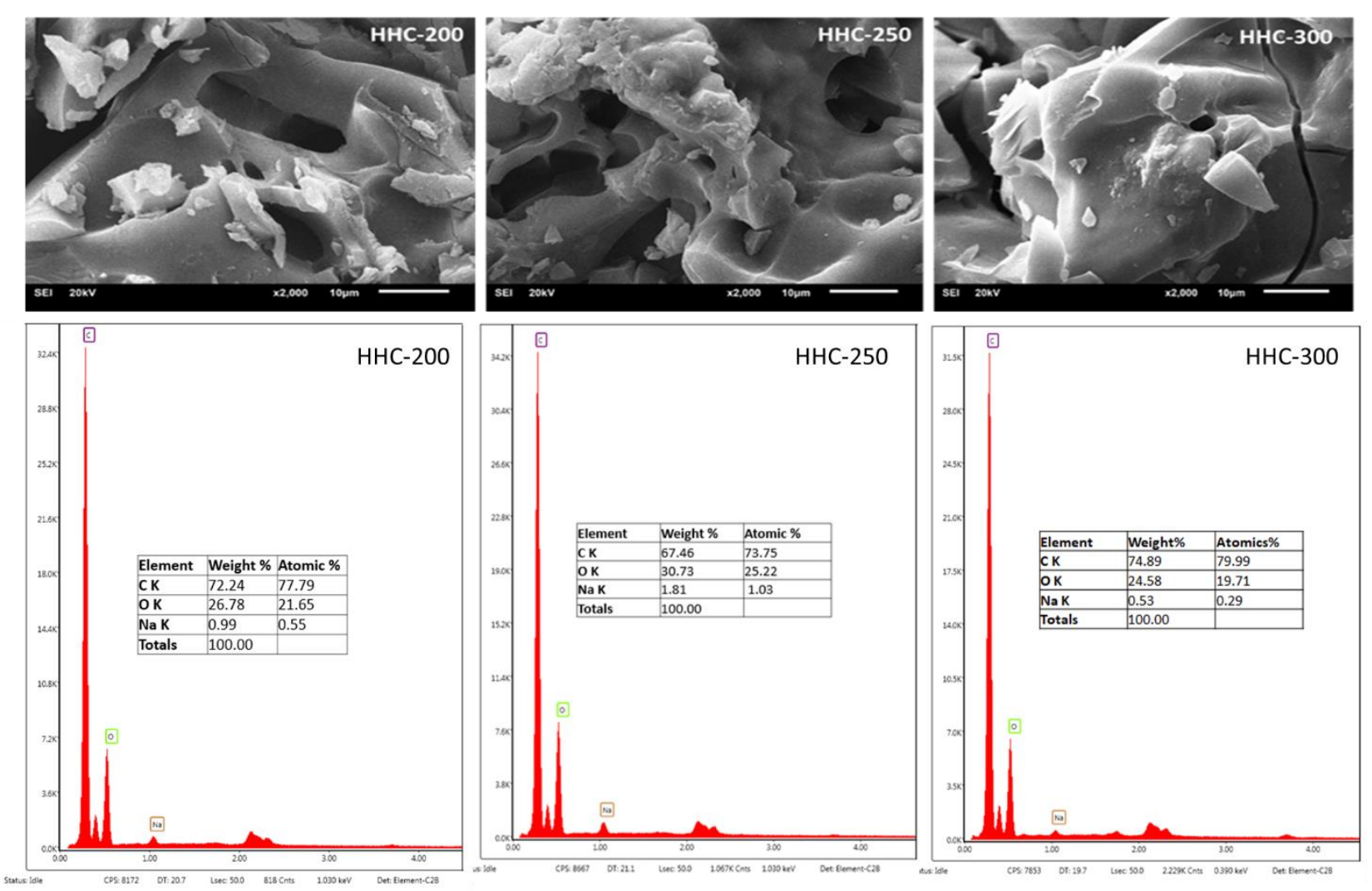

Figure 1. SEM and EDS images of HHC samples

Raman spectra of HHC samples different temperatures are given in Figure 2. Here in G and D peaks are defined in the Raman spectra of carbon structures. [50] The intensity of peak $\mathrm{G}\left(\mathrm{I}_{\mathrm{G}}\right)$ refers to regular crystal structures, whereas the intensity of peak $\mathrm{D}\left(\mathrm{I}_{\mathrm{D}}\right)$ refers to irregular crystal structures. Besides, by calculating the $\mathrm{I}_{\mathrm{D}} / \mathrm{I}_{\mathrm{G}}$ ratio, information about the crystal structure of the produced sample is obtained [51]. At 200-300 ${ }^{\circ} \mathrm{C}$, it is observed that there is a trend from strip $\mathrm{G}$ to strip D. In the spectra of activated samples at 200 and $300{ }^{\circ} \mathrm{C}$, these two strips overlap as a single strip. The peak separation at 250 degrees was clearly observed. 


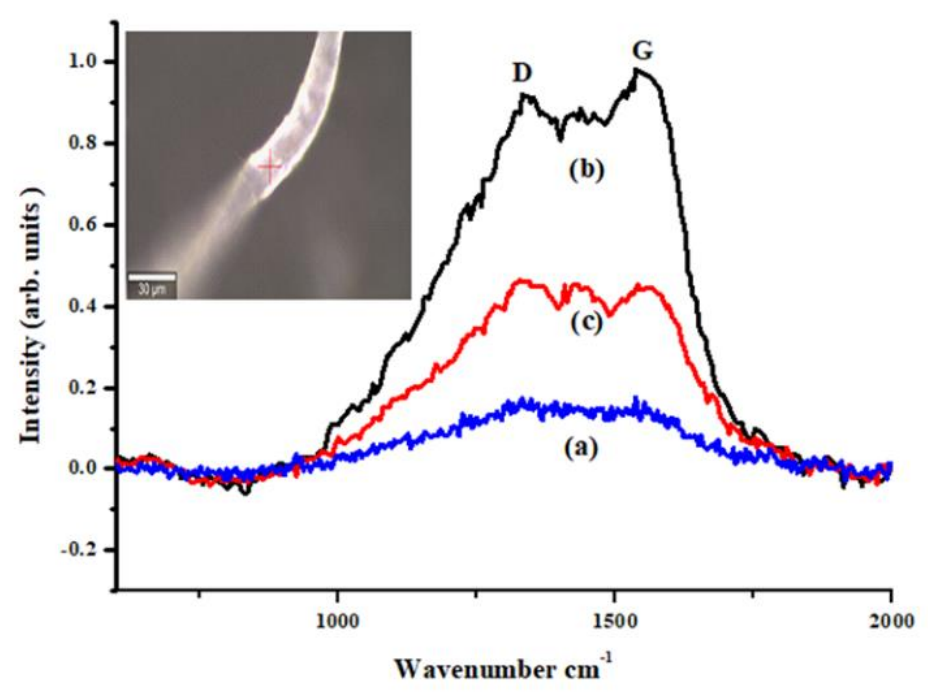

Figure 2. Raman spectra of samples activated under a) $\left.200^{\circ} \mathrm{C} \mathrm{b}\right) 250^{\circ} \mathrm{C} \mathrm{c}$ ) $300^{\circ} \mathrm{C}$ (Inset: Raman image of carbon activated by $\mathrm{Na}_{2} \mathrm{CO}_{3}$ nanorod recorded of the incident laser and scattered light)

Adsorption isotherms of ACs obtained from human hair using nitrogen $\left(\mathrm{N}_{2}\right)$ gas at $77 \mathrm{~K}$ are given in Figure 3. The surface area of HHC-250 was calculated as $10.233 \mathrm{~m}^{2} \mathrm{~g}^{-1}$ by the Brunauer-Emmett-Teller (BET) method in Table 1. HHC was reacted with $\mathrm{Na}_{2} \mathrm{CO}_{3}$ and $\mathrm{N}_{2}$ (g) at different temperatures was burned in a tube furnace and carbonized. The HHCs were then activated by degassing under vacuum at $250{ }^{\circ} \mathrm{C}$.

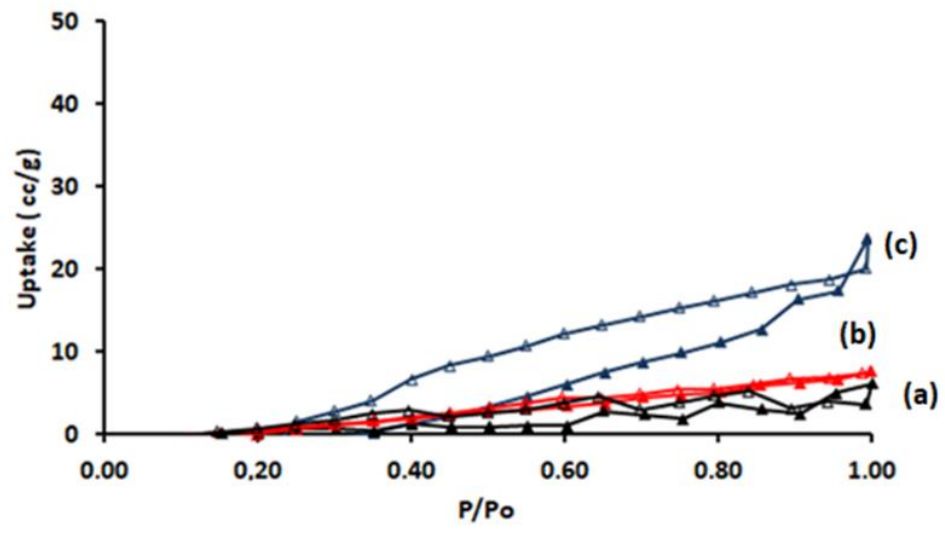

Figure 3. Adsorption (filled marker) and desorption (empty marker) isotherms of samples activated with a) $\left.\left.200^{\circ} \mathrm{C}, b\right) 250,{ }^{\circ} \mathrm{Cc}\right) 300^{\circ} \mathrm{C}$

HHCs displayed a Type-IV isotherm with indicating the existence of micro-mesoporous structures [52] As it is clear from Figure 4 that HHCs were similar in pore size distribution to $1 \sim 1.98 \mathrm{~nm}$ (micro-pores) and 2 4 $\mathrm{nm}$ (meso-pores). 


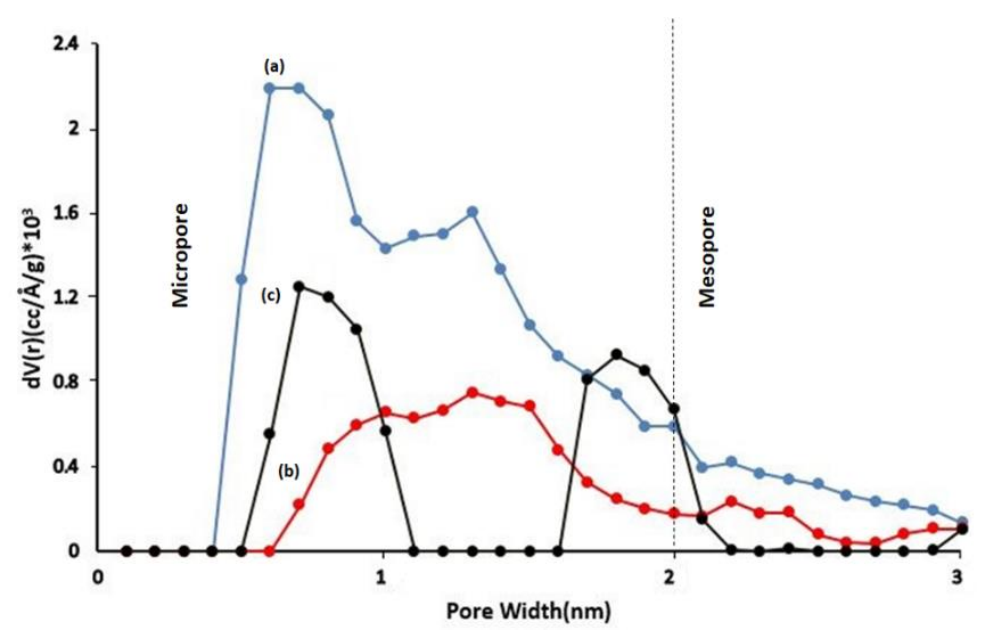

Figure 4. Pore width distribution results of a) $200^{\circ} \mathrm{C}$ b) $250{ }^{\circ} \mathrm{Cc}$ c) $300^{\circ} \mathrm{C} \mathrm{Na}_{2} \mathrm{CO}_{3}$ with DFT-method

Table 1. Surface areas of the AC samples

\begin{tabular}{|l|l|}
\hline Sample name & BET $\left(\mathrm{m}^{2} \mathrm{~g}^{-1}\right)$ \\
\hline HHC-200 $^{\circ} \mathbf{C}$ & 1.184 \\
\hline HHC-250 $^{\circ} \mathbf{C}$ & 10.233 \\
\hline HHC-300 $^{\circ} \mathbf{C}$ & 2.423 \\
\hline
\end{tabular}

\subsection{Electrochemical Measurements of HHC Electrodes}

Since the best surface parameters were obtained for HHC-250 sample the rest of the experiments were carried out by the usage of this sample as a composite modifier. Figure 5 shows the comparison of the voltammograms obtained for different amounts of HHC-250 $(1,2,4,6$ and $8 \%$ by mass of the electroactive material). Peak currents of the voltammograms showed a linear increase by the amount of the HHC up to $4 \%$ then decreased by $6 \%$ and $8 \%$ HHC-250 additions (Figure 5). Therefore the optimum amount of HHC-250 was determined as $4 \%$ for the upcoming optimizations.

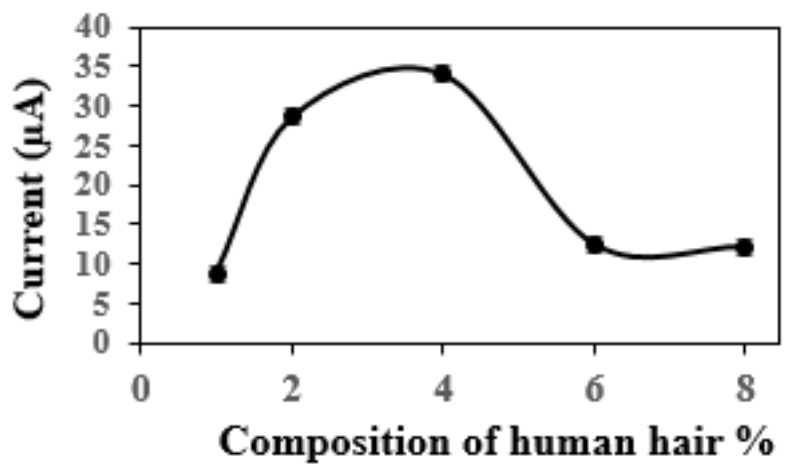

Figure 5. Optimization graph of the effect of HHC-250 amount 1\%,2\%,4\%,6\%, 8\% in graphite powder ( $6 \mathrm{M} \mathrm{KOH}$ solution over a potential range from -1.0 to $0 \mathrm{~V}$, at room temperature) 
$\mathrm{CV}$ is a commonly used method for the analysis of electrochemical transfer mechanism on the electrode surface. Here the case is an examination of the charge transfer mechanism between the electrode surface and the electrolyte. To explain the charge transfer rate for all of the HHC-200; HHC-250 and HHC-300 modified electrodes were measured at different scan rates of 5 (a), 20 (b), 50 (c) and 100 (d) $\mathrm{mV} \mathrm{s}^{-1}$ in Figure 6. Voltammograms were evaluated by the calculation of the peak areas of the completed cycles. These areas are divided into the effective electrochemical active mass of the corresponding electrode in order to achieve specific capacitance (Csp) value. Results showed that (Table 2) the peak areas increased by the increment of the scan rates.
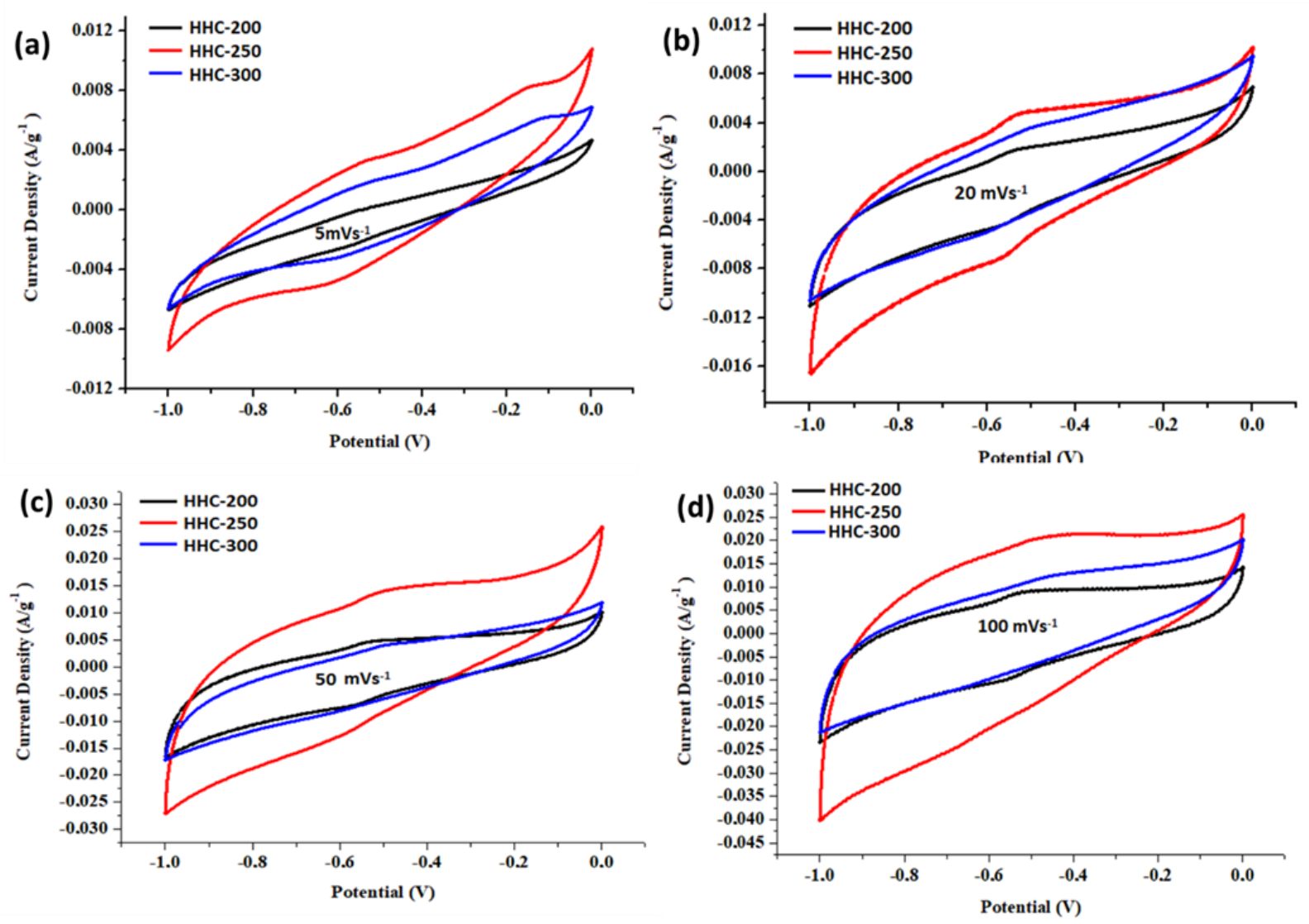

Figure 6. Cyclic voltammograms of HHC samples at a scan rate from a) $5 \mathrm{mV} \mathrm{s}^{-1}$ b) $20 \mathrm{mV} \mathrm{s}^{-1}$ c) $50 \mathrm{mV} \mathrm{s}$ $\left.{ }^{1} \mathrm{~d}\right) 100 \mathrm{mV} \mathrm{s}^{-1}$

According to the $\mathrm{CV}$ measurements, among all modifications HHC-250 revealed the best current increment values for all of the scan rates applied (Figures 6 and 7a). Additionally, Figure 8 shows the increment of electrochemical activity of the HHC-250 modified electrode by the increasing scan rates $(5,20,50$, and 100 $\mathrm{mV} \mathrm{s}^{-1}$ ). It can be seen that the peak area of the HHC-250 modified electrode widened by the increasing rate of the scan. The best result was observed for the highest scan rate of $100 \mathrm{mV} \mathrm{s}^{-1}$. Subsequently, electrochemical activity of the HHC modified electrodes was examined by impedimetric analysis. Two sides of the Nyquist plots were observed compatible with the Warburg model. In Figure 7b, it can be seen that semicircle of the HHC modified electrodes show differences from each other. Warburg model says that if the semicircle of the plot gets larger due to the electrons face with a resistance impedance gets higher. Here HHC-250 modified electrode shows the smallest semicircle part and the slope after semicircle is the highest among other modified electrodes (HHC-200 and HHC-300). This situation is explained with the charge transfer capability of the electrode is the best for HHC-250 modified electrode. To sum up, HHC250 modified electrode has shown the best electrochemical behavior and this is attributed to its unique surface properties and electroactive cavities. 

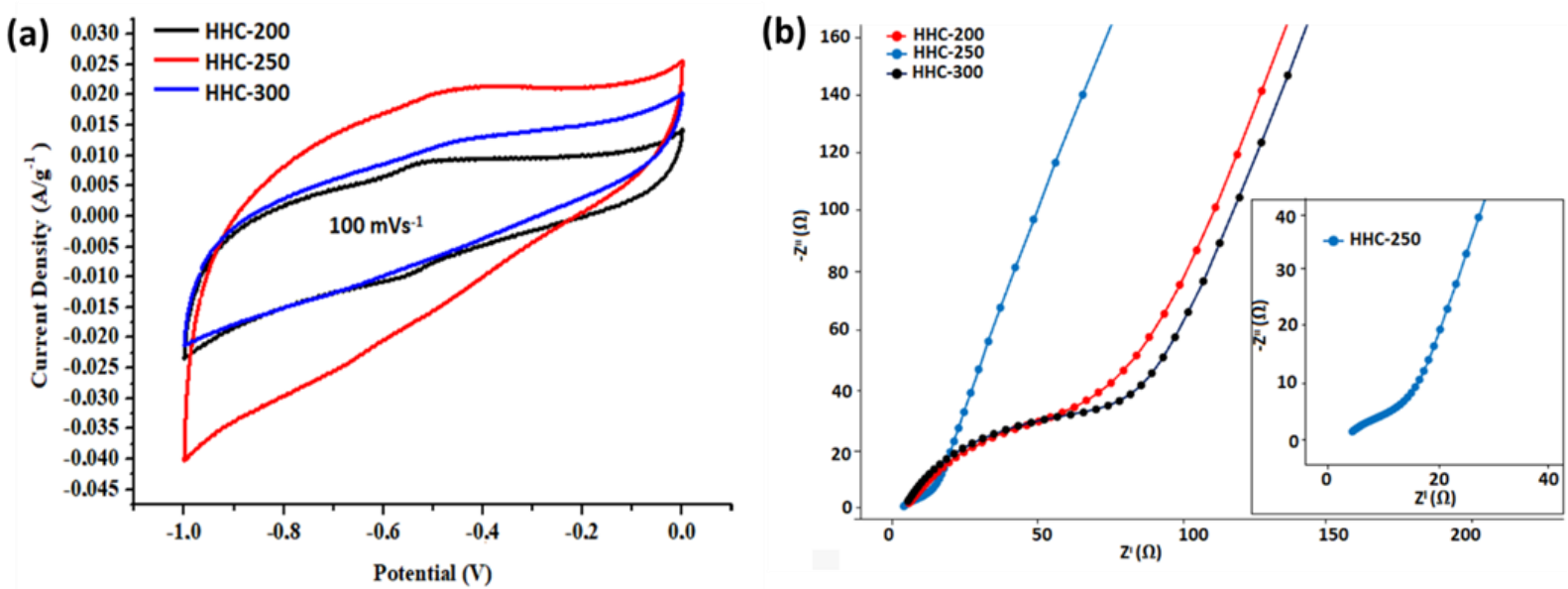

Figure 7. a) Cyclic voltammograms of HHC samples at the scan rate from 5 to $100 \mathrm{mV} \mathrm{s}^{-1}$ b) EIS results were measured in a frequency range of $10^{-1}$ to $10^{4} \mathrm{~Hz}$ in $6 \mathrm{M} \mathrm{KOH}$ solution, inset: HHC-250

Typically, such type of exohedral carbons show SBET of only $300-500 \mathrm{~m}^{2} \mathrm{~g}^{-1}$, and usually reveals with a moderate capacitance range of only $20-100 \mathrm{~F} \mathrm{~g}^{-1}$. Nevertheless, its high graphitic structure and outer surface area make these materials very convenient for fast charge and discharge applications [53-55]. Recent studies exhibited moderate Csp values (18-137 $\left.\mathrm{F} \mathrm{g}^{-1}\right)$ for single-wall and multi-wall CNTs in $6 \mathrm{M} \mathrm{KOH}$ aqueous electrolyte [56].

Similar studies with very efficient capacitance values using human hair are available in the literature [5760]. In these studies, composite materials were created with human hair, either the material itself was used as an electrode [58] or the developed material was used to increase electrochemical activity [59-60]. A wide range of responses from $58 \mathrm{~F} \mathrm{~g} \mathrm{~g}^{-1}$ to $264 \mathrm{~F} \mathrm{~g}^{-1}$ was obtained from these studies. The difference of the presented study from the above-mentioned studies is that the hair activated with $\mathrm{Na}_{2} \mathrm{CO}_{3}$ is applied directly in the SC structure. It is believed that these first performance outputs, which are obtained when advanced modifications are made as in these studies, can be improved much more.

In theory, if the surface area and electrolyte concentration get higher, obtained capacitance increases. Generally, the double layer capacitance of carbon is $15-50 \mu \mathrm{F} \mathrm{cm}^{-2}$. This value can be changed according to the electrode/solution interface, the type of carbon and its preparation process. If the average value of this $15-50 \mu \mathrm{F} \mathrm{cm}^{-2}$ interval is taken as $25 \mu \mathrm{F} \mathrm{cm}^{-2}$ and the specific area of carbon is assumed as $1000 \mathrm{~m}^{2} \mathrm{~g}^{-}$ ${ }^{1}$, the ideal attainable capacitance of this carbon would be $250 \mathrm{~F} \mathrm{~g} \mathrm{~g}^{-1}$. When the accessibility of carbon surface exposed to the electrolyte is prevented just a few tens of $\mathrm{F} \mathrm{g}^{-1}$ in EDLC is obtained. The presented carbon possesses micropores essentially consisting of $<2 \mathrm{~nm}$ in size. This area is often hard or non-accessible for common ions [54]. 


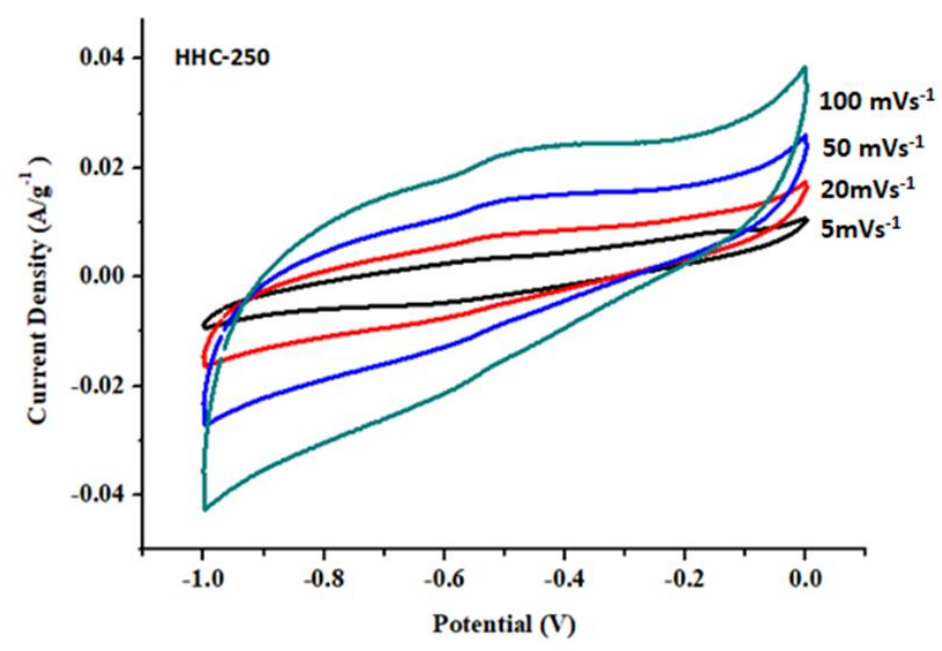

Figure 8. Cyclic voltammograms of HHC-250 samples at scan rate from 5 to $100 \mathrm{mV} \mathrm{s}^{-1}$

Table 2. Potentiometric capacitances of the HHC samples at different scan rates

\begin{tabular}{|l|l|l|l|}
\hline \multicolumn{2}{|l|}{ Scan Rate $\left(\mathrm{mV} \mathrm{s}^{-1}\right)$} & $\mathrm{C}_{\text {SP }}\left(\mathrm{F} \mathrm{g}^{-1}\right)$ of samples. \\
\hline & HHC-200 & HHC-250 & HHC-300 \\
\hline 5 & 1.59 & 5.07 & 3.08 \\
\hline 20 & 4.15 & 9.84 & 5.25 \\
\hline 50 & 8.12 & 18.09 & 7.79 \\
\hline 100 & 13.46 & $\mathbf{2 6 . 8 8}$ & 14.86 \\
\hline
\end{tabular}

Figure 9 shows the charge/discharge cycling behavior of HHC-250 modified electrode at a constant scan rate of $100 \mathrm{mV} \mathrm{s}^{-1}$ between -1 and $0 \mathrm{~V}$ potential values for 1000 cycles. The Csp values are found to be stable even after the 1000 cycles and exhibited Csp repeatability of about $92.66 \%$. The initial specific capacitance is still maintained and sustainable, suggesting that the HHC-250 modified electrode has excellent charge/discharge ability.

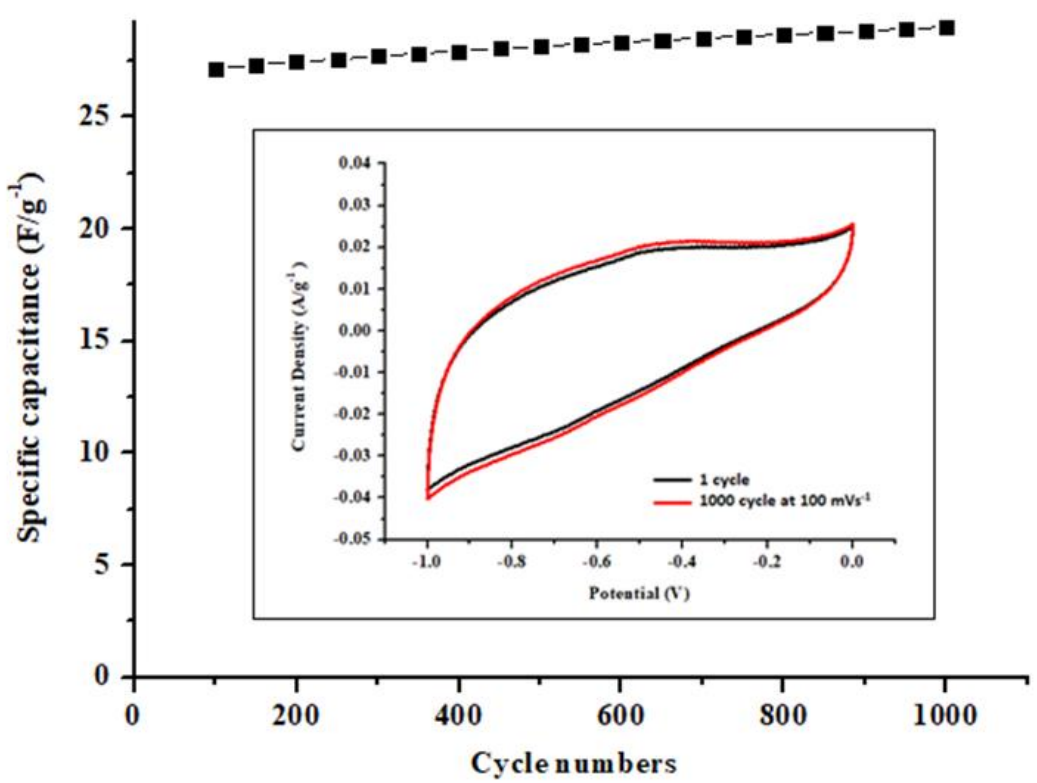

Figure 9. Cyclic stability of HHC-250 electrode at $100 \mathrm{mV} \mathrm{s}^{-1}$, inset shows the comparison of the $1000^{\text {th }}$ CV cycle with the $1^{\text {st }} \mathrm{CV}$ cycle at $100 \mathrm{mV} \mathrm{s}^{-1}$ 


\section{RESULTS}

$\mathrm{Na}_{2} \mathrm{CO}_{3}$ doped $\mathrm{AC}$ from waste Turkish human hair was successfully synthesized. $\mathrm{Na}_{2} \mathrm{CO}_{3}$ doped $\mathrm{HHCs}$ were calcinated at different activation temperatures in the range of $200-300{ }^{\circ} \mathrm{C}$. The synthesized $\mathrm{Na}_{2} \mathrm{CO}_{3}$ doped HHCs were morphologically and electrochemically characterized and applied as a SC material. Among all above mentioned HHC-based materials, HHC-250 samples showed a microrod shaped porous structure plus divergent functional groups attached to the surface and relatively very large specific surface area $\left(\mathrm{S}_{\mathrm{BET}}=10.233 \mathrm{~m}^{2} \mathrm{~g}^{-1}\right)$, which contains pore size distribution to $1 \sim 1.98 \mathrm{~nm}$ (micro-pores) and $2 \sim 4 \mathrm{~nm}$ (meso-pores). Hybrid dislocations (cracks in the structure) were formed as a result of explosions in the HHC structure activated at $250{ }^{\circ} \mathrm{C}$. The specific capacitance of the HHC-250 modified electrode reached to $26.88 \mathrm{~F} \mathrm{~g}^{-1} \mathrm{Csp}$ value at the scan rate of $100 \mathrm{mV} \mathrm{s}^{-1}$. The developed electrode has stayed stable even after 1000 cycles of charge/discharge operations. As a result, $\mathrm{Na}_{2} \mathrm{CO}_{3}$ activated $\mathrm{HHC}$ at $250{ }^{\circ} \mathrm{C}$ obtained from waste human hairs is a providing candidate for SC electrode material applications.

\section{ACKNOWLEDGEMENT}

We are very thankful to Mugla Sitkı Koçman University Scientific Research Project Office for their contribution to this work by providing some of the chemicals with the 17/231 numbered project.

\section{CONFLICTS OF INTEREST}

No conflict of interest was declared by the authors.

\section{REFERENCES}

[1] Liu, C., Li, F., Ma, L. P., Cheng, H. M., "Advanced Materials for Energy Storage", Advanced Materials, 22: 28-62, (2010).

[2] Frackowiak, E., "Carbon materials for supercapacitor application", Physical Chemistry Chemical Physics, 9: 1774-1785, (2007).

[3] Rani, J.R., Thangavel, R., Oh, S-I., Lee, Y.S., Jang, J-H., "An Ultra-High-Energy Density Supercapacitor; Fabrication Based on Thiol-functionalized Graphene Oxide Scrolls, Nanomaterials", Nanomaterials, 9: 148-160, (2019).

[4] Wang, Q., Yan, J., Wang, Y., Wei, T., Zhang, M., Jing, X., Fan, Z., "Three-dimensional flower-like and hierarchical porous carbon materials as high-rate performance electrodes for supercapacitors", Carbon, 67: 119-127, (2014).

[5] Obreja, V. V. N., "On the performance of supercapacitors with electrodes based on carbon nanotubes and carbon activated material", Physica E., 40: 2596-2605, (2008).

[6] Huggins, R. A., "Supercapacitors and electrochemical pulse sources", Solid State Ionics, 134: 179195, (2000).

[7] Jayalakshmi, M., Balasubramanian, K., "Simple Capacitors to Supercapacitors", International Journal of Electrochemical Science, 3: 1196-1217, (2008).

[8] Pech, D., Brunet, M., Durou, H., Huang, P., Mochalin, V., Gogotsi, Y., Taberna, P. L., Simon, P., "Ultrahigh-power micrometre-sized supercapacitors based on onion-like carbon", Nature Nanotechnology, 5: 651-654, (2010).

[9] Ahmed, S., Bhat, M. Y., Rafat, M., Hashmi, S. A., " Low-temperature thermal exfoliation of graphene oxide for high performance supercapacitor", Journal of Materials Science and Surface Engineering, 22: 993-1002, (2017). 
[10] Simon, P., Gogotsi, Y., "Materials for electrochemical capacitors", Nature Materials, 7: 845-854, (2008).

[11] Lota, G., Fic, K., Frackowiak, E., "Carbon nanotubes and their composites in electrochemical applications", Energy \& Environmental Science, 4: 1592-1605, (2011).

[12] Wang, G., Zhang, L., Zhang, J., "A review of electrode materials for electrochemical supercapacitors", Chemical Society Reviews, 41: 797-828, (2012).

[13] Dong, X., Wang, X., Wang, L., Song, H., Li, X., Wang, L., Chan-Park, M.B., Li, C.M., Chen, P., "Synthesis of a MnO2-graphene foam hybrid with controlled $\mathrm{MnO} 2$ particle shape and its use as a supercapacitor electrode", Carbon, 50: 4865-4870, (2012).

[14] Kondrat, S., Perez, C. R., Presser, V., Gogotsi, Y., A. Kornyshev, A., "Effect of pore size and its dispersity on the energy storage in nanoporous supercapacitors", Energy \& Environmental Science, 5: 6474-6479, (2012).

[15] Zhai, Y., Dou, Y., Zhao, D., Fulvio, P. F., Mayes, R. T., Dai, S., "Carbon Materials for Chemical Capacitive Energy Storage", Advanced Materials, 23: 4828-4850, (2011).

[16] Qian, W., Sun, F., Xu, Y., Qiu, L., Liu, C., Wang, S., Yan, F., "Human hair-derived carbon flakes for electrochemical supercapacitors", Energy \& Environmental Science, 7: 379-386, (2014).

[17] Hashmi, S.A., "Supercapacitor: an emerging power source", National Academy Science Letters, 27: 27-46, (2004).

[18] Wu, Z.S., Sun, Y., Tan, Y.Z., Yang, S., Feng, X., Müllen, K.,"Three-Dimensional Graphene-Based Macro- and Mesoporous Frameworks for High-Performance Electrochemical Capacitive Energy Storage", Journal of the American Chemical Society, 134: 19532-5, (2012).

[19] Uğurlu, M., Kula, I., Karaoğlu, M.H., Arslan, Y., "Removal of Ni(II) ions from aqueous solutions using activated carbon prepared from olive stone by $\mathrm{ZnCl} 2$ activation", Environmental Progress and Sustainable Energy, 28: 547-557, (2009).

[20] Karacan, F., Karacan, S.," Production and Characterization of Activated Carbon from ÇanakkaleÇan Lignite by $\mathrm{KOH}$ and $\mathrm{ZnCl} 2$ Activation", Pamukkale University Journal of Engineering Sciences, 20: 1-8, (2014).

[21] Yakout, S. M., Sharaf El-Deen, G., "Characterization of activated carbon prepared by phosphoric acid activation of olive stones", Arabian Journal of Chemistry, 9: 1155-1162, (2016).

[22] Zhang, L., Gu, H., Sun, H., Cao, F., Chen, Y., Chen, G. Z., "Molecular level one-step activation of agar to activated carbon for high performance supercapacitors", Carbon, 132: 573-579, (2018).

[23] Muthulakshmi, B., Kalpana, D., Pitchumani, S., Renganathan, N. G., "Electrochemical deposition of polypyrrole for symmetric supercapacitors", Journal of Power Sources, 158: 1533-1537, (2006).

[24] Wang, J., Naser, N., Angnes, L., Wu, H., Chen, L., "Metal-Dispersed Carbon Paste Electrodes", Analytical Chemistry, 64: 1285-1288, (1982).

[25] Naik, R., Wen, G., Dharmaprakash M.S., Hureau, S., Uedono, A., Wang, X., Liu, X., Cookson, P.G., Smith, S.V., "Metal ion binding properties of novel wool powders", Journal of Applied Polymer Science, 115: 1642-1650, (2010). 
[26] Cui, H., Zheng, J, Zhua, Y., Wang, Z., Jia, S., Zhu, Z., "Graphene frameworks synthetized with $\mathrm{Na} 2 \mathrm{CO} 3$ as a renewable water-soluble substrate and their high rate capability for supercapacitors", Journal of Power Sources, 293: 143-150, (2015).

[27] Zhang, L. L., Gu, Y., Zhao, X. S., "Advanced porous carbon electrodes for electrochemical capacitors", Journal of Materials Chemistry A, 1: 9395-9408, (2013).

[28] Baltenneck, F., Bernard, B.A., Garson, J. C., Engstrom, P., Riekel, C., Leroy, F., Franbourg, A., Doucet, J., "Study of the keratinization process in human hair follicle by X-ray microdiffraction", Cellular and Molecular Biology, 46: 1017-1024, (2000).

[29] Gnerlich, M., Ben-Yoav, H., Culver, J. N., Ketchum, D. R., Ghodssi, R., "Selective deposition of nanostructured ruthenium oxide using Tobacco mosaic virus for micro-supercapacitors in solid Nafion electrolyte", Journal of Power Sources, 293: 649-656, (2015).

[30] Yun, Y. S., Park, M. H., Hong, S. J., Lee, M. E., Park, Y. W., Jin, H.J., "Hierarchically Porous Carbon Nanosheets from Waste Coffee Grounds for Supercapacitors", ACS Applied Materials \& Interfaces, 7: 3684-3690, (2015).

[31] Ajuria, J., Redondo, E., Arnaiz, M., Mysyk, R., Rojo, T., Goikolea, E., "Lithium and sodium ion capacitors with high energy and power densities based on carbons from recycled olive pits", Journal of Power Sources, 359: 17-26, (2017).

[32] Madhu, R., Sankar, K.V., Chen, S.M., Selvan, R.K., "Eco-friendly synthesis of activated carbon from dead mango leaves for the ultrahigh sensitive detection of toxic heavy metal ions and energy storage applications", RSC Advances, 4: 1225-1233, (2014).

[33] Huang, G., Kang, W., Xing, B., Chen, L., Zhang, C., "Oxygen-rich and hierarchical porous carbons prepared from coal based humic acid for supercapacitor electrodes", Fuel Processing Technology, 142: 1-5, (2016).

[34] Gupta, K. K., Aneja, K. R., Rana, D., "Current status of cow dung as a bioresource for sustainable development", Bioresources and Bioprocessing, 3: 28, (2016).

[35] Iriarte-Velasco, U., Sierra, I., Zudaire, L., Ayastuy, J. L., "Conversion of waste animal bones into porous hydroxyapatite by alkaline treatment: effect of the impregnation ratio and investigation of the activation mechanism", Journal of Materials Science, 50: 7568-7582, (2015).

[36] Wang, J., Senkovska, I., Kaskel, S., Liu, Q., "Chemically activated fungi-based porous carbons for hydrogen storage", Carbon, 75: 372-380, (2014).

[37] Xuan, H., Lin, G., Wang, F., Liu, J., Dong, X., Xi, F., "Preparation of biomass-activated porous carbons derived from torreya grandis shell for high-performance supercapacitor", Journal of Solid State Electrochemistry, 21: 2241-2249, (2017).

[38] Chen, D., Chen, X., Sun, J., Zheng, Z., Fu, K., "Pyrolysis polygeneration of pine nut shell: Quality of pyrolysis products and study on the preparation of activated carbon from biochar", Bioresource Technology, 216: 629-636, (2016).

[39] Sarswat, A., Mohan, D.,"Sustainable development of coconut shell activated carbon (CSAC) \& a magnetic coconut shell activated carbon (MCSAC) for phenol (2-nitrophenol) removal", RSC Advances, 6: 85390-85410, (2016). 
[40] Ahmed, M. J., Islam, M. A., Asif, M., Hameed, B. H., "Human hair-derived high surface area porous carbon material for the adsorption isotherm and kinetics of tetracycline antibiotics", Bioresource Technology, 243: 778-784, (2017).

[41] Gupta, A., "Human Hair "Waste" and Its Utilization: Gaps and Possibilities", Journal of Waste Management, 1-17, (2014).

[42] Lee, L. D., Baden, H.P., "Chemistry and Composition of the Keratins", International Journal of Dermatology, 14: 161 -171, (1975).

[43] Chen, M., Kang, X., Wumaier, T., Dou, J., Gao, B., Han, Y., Xu, G., Liu, Z., Zhang, L., "Preparation of activated carbon from cotton stalk and its application in supercapacitor", Journal of Solid State Electrochemistry, 17: 1005-1012, (2013).

[44] Yun, Y. S., Park, M. H., Hong, S. J., Lee, M. E., Park, Y. W., Jin, H. J., ACS Applied Materials \& Interfaces, 7: 3684-3690, (2015).

[45] Bal Altuntaş, D., Nevruzoğlu, V., Dokumacı, M., Cam, Ş., "Synthesis and characterization of activated carbon produced from waste human hair mass using chemical activation", Carbon Letters, 29: 1-7, (2019).

[46] Lewandowski, A., Olejniczak, A., Galinski, M., Stepniak, I., "Performance of carbon-carbon supercapacitors based on organic, aqueous and ionic liquid electrolytes", Journal of Power Sources, 195: 5814-5819, (2010).

[47] Wu, F.C., Tseng, R.L., Hu, C.C., Wang, C.C., "Effects of pore structure and electrolyte on the capacitive characteristics of steam- and $\mathrm{KOH}$-activated carbons for supercapacitors", Journal of Power Sources, 144: 302-309, (2005).

[48] Igowsky, K, Pangerl, E. American Society of Trace Evidence Examiners., 44: 17-27, (2013).

[49] Mu, X., Du, J., Zhang, Y., Liang, Z., Wang, H., Huang, B., Zhou, J., Pan, X., Zhang, Z., Xie, E., "Construction of Hierarchical CNT/rGO-Supported MnMoO4 Nanosheets on Ni Foam for HighPerformance Aqueous Hybrid Supercapacitors", ACS Applied Materials \& Interfaces, 9: 3577535784, (2017).

[50] Yan, W., Daniel Charles, A., McCreery Richard, L., "Raman spectroscopy of carbon materials: structural basis of observed spectra", Chemistry of Materials, 2: 557-563, (1990).

[51] Tuinstra, F., Koenig, J. L.,"Raman Spectrum of Graphite", Journal of Chemical Physics, 53: 1126, (1970).

[52] Yang, I., Kwon, D., Yoo, J., Kim, M. S., Jung, J. C., "Design of organic supercapacitors with high performances using pore size controlled active materials", Current Applied Physics, 19: 89-96, (2019).

[53] Frackowiak, E., Metenier, K., Bertagna, V., Beéguin, F., "Supercapacitor electrodes from multiwalled carbon nanotubes", Applied Physics Letters, 77: 2421, (2000).

[54] Frackowiak, E., Béguin, F., "Carbon materials for the electrochemical storage of energy in capacitors", Carbon, 39: 937-950, (2001).

[55] McDonough, J. K., Frolov, A. I., Presser, V., Niu, J., Miller, C. H., Ubieto, T., Fedorov, M. V., Gogotsi Y., "Influence of the structure of carbon onions on their electrochemical performance in supercapacitor electrodes", Carbon, 50: 3298, (2012). 
[56] Frackowiak, E., Jurewicz, K., Delpeux, S., Béguin, F., "Nanotubular materials for supercapacitors", Journal of Power Sources, 97-98: 822-825, (2001).

[57] Satish, R., Aravindan, V., Chui Ling, W., Woei Ng, K., Madhavi, S., "Macroporous carbon from human hair: A journey towards the fabrication of high energy Li-ion capacitors", Electrochimica Acta, 182: 474-481, (2015).

[58] Si, W., Zhou, J., Zhang, S., Li, S., Xing, W., Zhuo, S., "Tunable N-doped or dual N, S-doped activated hydrothermal carbons derived from human hair and glucose for supercapacitor applications", Electrochimica Acta, 107: 397-405, (2013).

[59] Zhao, J., Gong, J., Zhou, C., Chenxu, M., Hu, R., Zhu, K., Cheng, K., Ye, K., Yan, J., Cao, D., Zhang, X., Wang, G., "Utilizing human hair for solid-state flexible fiber-based asymmetric supercapacitors", Applied Surface Science, 508: 145260, (2020).

[60] Liu, W., Feng, K., Zhang, Y., Yu, T., Han, L., Lui, G., Li, M., Chiu, G., Fung, P., Yu, A. "Hairbased flexible knittable supercapacitor with wide operating voltage and ultra-high rate capability", Nano Energy, 34: 491-499, (2017). 